\title{
Guideline for Innovation Management Design of Home Bathroom Environment to Help Reduce Accident Risk among Elderly
}

\author{
$\operatorname{Phd}(\mathrm{c})$. Chartchay Junprateep \\ Asst. Prof. Dr. Somchai Seviset \\ Assoc. Prof. Dr. Songwut Eakwutvongsa \\ King Mongkut's Institute of Technology Ladkrabang (KMITL), \\ No.1, Soi Chalongkrung 1, Chalongkrung Road, \\ Ladkrabang, Bangkok, 10520, Thailand
}

Doi: 10.36941/mjss-2020-0017

\section{Abstract}

The present research was aimed to investigate the space and accident risk factors of elderly in home bathroom, risk problems, and the current functional limitations for elderly. The study investigated spaces of bathrooms in 30 homes currently living by elderly by conducting an assessment of proper bathroom environmental features, and interviews with the elderly at home. Results of assessment of bathroom spaces of all homes under the study categorized into 5 aspects of importance suggested a low level of propriety $(\bar{X}=$ 2.22 , S.D.=0.85). For sub-aspects of importance, suitable size and proportion were at a low level $(\bar{X}=2.18$, S.D.=0.73), and the design materials were at a lowest level $(\bar{X}=1.26, S . D .=0.41)$. In conclusion, all of the studied spaces were found with inappropriate environment to accommodate the use by elderly. The researcher recognized the problems, roles, and importance of involved individuals and thus proposed guidelines for the design of home bathroom under the universal design concept so as to guide good standards as a key factor for taking improvement action for accident prevention and preparation of sound environment for elderly.

Keywords: Innovation management design, Environmental, Bathroom for Elderly, Accident

\section{Introduction}

In Thailand, more than 1000 deaths of elderly per year or average 3 deaths per day were reported, which were mostly occurred at home due to falls including fall on even floor, slipping, stumbling, tripping, bumping or pushing by others, or fall on uneven floors. The number of elderly tends to increase each year and the situation associated with falls has become one among major problems in this population group. Epidemiological data indicated the incidence of falls among those aged over 65 and 85 years for as high as 30\% and 50\%, respectively. According to Thailand 2nd National Plan on the Elderly (2002-2021), Chapter 2: Strategy on the Elderly Promotion and Development defines the measure to promote and support appropriate and safe housing and environment. In this respect, it is urgent that basic utilities are prepared for elderly because inappropriate domestic environment can be hazardous (Lan et al., 2009) or interfere with their daily living (Julie \& Joseph, 2004) and might affect the life of elderly. In addition, good design concept will facilitate the elderly's better quality in performing activities of daily living (O'Meara and Smith, 2006). 
The above information reflected that fall is one among crucial problems that mitigates the elderly's quality of life, and consequently increases the burden of relatives and family members including caregiver. Preventing fall or reducing risk of accidents in elderly is thus a key measure to prevent their injuries and disabilities, enable their self-care, and reduce the burden of relatives and family members. The current study is the starting point to investigate home bathroom environment as a primary risk space and also other factors related to safety considerations that help effectively support elderly living behaviors. It is expected that, through publicizing, the movement will be generated and the concept of design for all; universal design will be recognized. In this way, it will not only benefit the elderly group but also other groups including disabled persons, children, and disadvantaged groups.

\section{Research Objective}

1) Investigate the space and risk factors of bathroom accident in elderly.

2) To recommend guidelines for modification of appropriate home bathroom environment for elderly.

\section{Research Conceptual Framework}

On risk factors of bathroom accident among elderly. The researcher explored factors that affect the types of activities and use behavior related to the use of bathroom space by elderly, including various factors that affect the design of bathroom environment, by using the conceptual framework of factors contributing to successful use of environment. Holistic environment was considered including 3 factors namely: appropriate physical environment; needs of users; and policy and attitude of caregiver to support the use of outdoor spaces. These 3 factors were covered in this study in order to explore guidelines for the design of appropriate building environment. Based on the review of literature both domestic and oversea and also the opinions of experts, the conclusions of good environment evaluation were drawn according to the following 5 features (Calkins 1988; Marsh 1981; Weisman 1981b).

1. Safety for elderly means environmental condition that is safe in terms of both the accident prevention when use and fall prevention.

2. Support for self-dependence means environmental condition that is supportive to the use by elderly themselves.

3. Support for brain functional system means environmental condition that reduces stress and stimulates brain use.

4. Support for the use means environmental condition that promotes outdoor use in tropical climate.

5. Support for long-term maintenance means environmental condition that is easy to care and functions effectively.

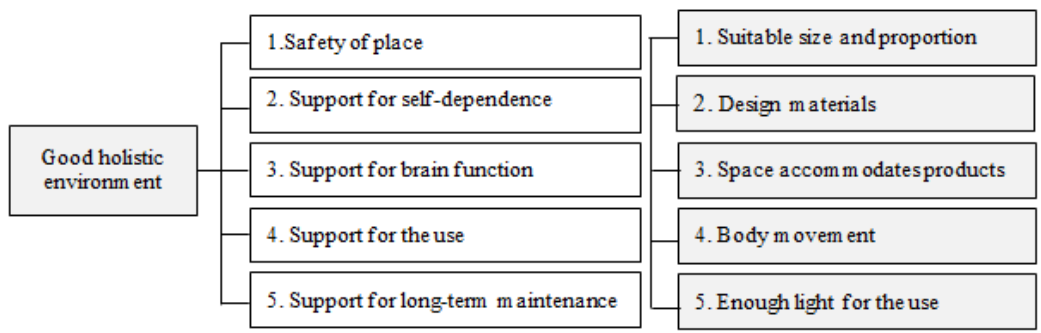

Fig 1: Conceptual framework for investigation of suitable environmental factors 


\section{Methodology}

This research employed a qualitative research approach of survey research type, with the following procedures.

1) Reviewing the design principles and concepts including other conditions that affect material use and home bathroom environmental space for elderly.

2) Developing an evaluation form on the features of material use and home bathroom environmental space for elderly.

3) Selecting sample area and sample population by means of purposive sampling considering the homes with the elderly actually living all day.

4) Conducting a survey and evaluation of material use and bathroom environmental space in the elderly's homes, observing and recording space using behavior, and interviewing with the elderly.

5) Analyzing and processing the survey results to identify the current problems of space condition, considering the relation of space use with the conditions of material use and home bathroom environmental space, and proposing key features of appropriate environmental conditions for elderly.

\subsection{Population and sample}

The government assigned Phitsanulok province as the area to take prompt action on the 20-Year National Strategic Framework (2016 - 2036) regarding the support for ageing society and as the area to formulate 10-Year Development Strategies for Ageing Society. In this light, the researcher thus placed specific importance on selecting the province as the area for investigation by a purposive sampling method to recruit 30 homes in the area of Phitsanulok, Thailand. The consideration criteria focused on the homes with the elderly actually living all day so as to capture space use behavior and various contexts of all routine activities.

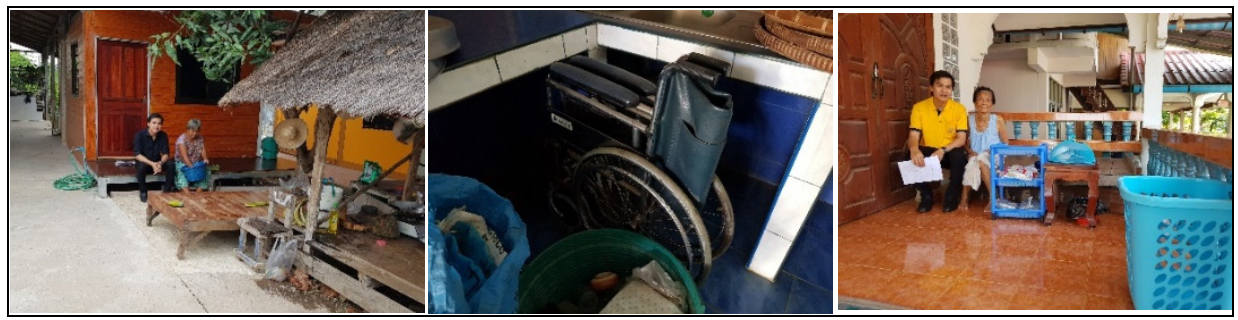

Fig 2: Some selected pictures of field activities in the study areas of bathrooms in the homes currently living by elderly

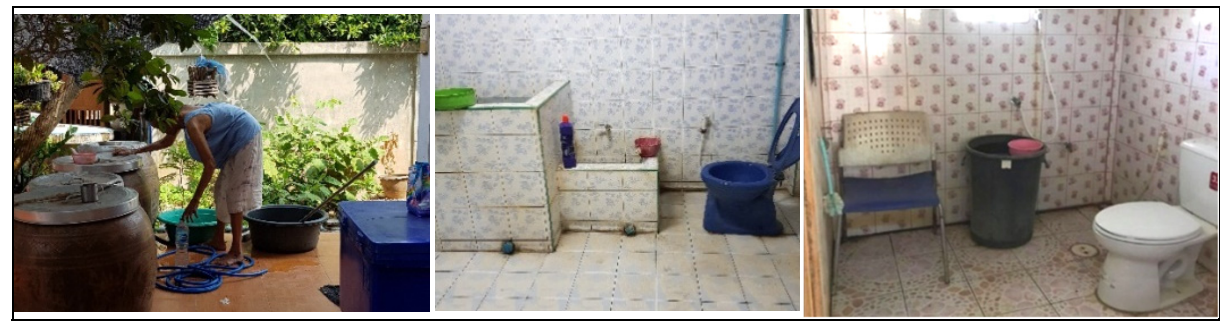

Fig 3: Some selected pictures of field activities in the study areas of bathrooms in the homes currently living by elderly 
The researcher hoped that this research results will help support the government policy and provide the design work for solving problems, reducing risk of fall accident among elderly due to inappropriate bathroom environment and other existing problems in the current ageing society.

\subsection{Research instrument}

To ensure technical validity of this research, the researcher employed the following instruments.

1. Informal interviews were performed to make clear conclusions of data and needs of the sample from the interviews with elderly group as key informants in Phrompiram district of Phitsanulok province, which were then concluded to guide the study.

2. Survey was conducted to investigate the study area, analyze the factors and real situation in the homes actually living by the elderly. The focus was on the situations of problems and bathroom accident risk of elderly.

The above results were then submitted to experts for their review of content validity as determined by an index of item-objective congruent (IOC), and language validity. Content validity was reviewed by 3 experts with IOC of 0.86 referring to the following interpretation criteria.

- Item with IOC between 0.50-1.0o provides acceptable validity.

- Item with IOC $<0.50$ provides unacceptable validity and requires improvement

3. Research instrumentation took on the following procedural steps (Petchroj L, Chamniprasart A., 2006: 113-121).

- Step 1 Prepare the data, consider theories related to research objectives

- Step 2 Choose open-ended questions

- Step 3 Define the questions need to be asked

- Step 4 Draft the questionnaire for investigation by the scope of objectives and submit to experts for a review.

- Step 5 Prepare printed final questionnaires.

\subsection{Data collection}

1. Secondary data involves the data collected from relevant documents, texts, and similar research works.

2. Primary data involves the data collected with research instruments and the data captured from elderly group as guideline to implement the project.

\subsection{Data analysis}

The investigation of risk factors of bathroom accident among elderly involves the data conclusions drawn from relevant documents, texts, interviews, and survey. The data was then interpreted by means of statistical analysis to describe the characteristics of qualitative and quantitative variables in terms of arithmetic mean or $\overline{\mathrm{x}}$ and standard deviation or S.D.

The analysis was based on a 5-point rating scale of Likert scale, with the criteria shown below.

Mean scores 4.21 - 5.00 represent a highest level of propriety of bathroom for elderly.

Mean scores 3.41 - 4.20 represent a high level of propriety of bathroom for elderly.

Mean scores 2.61 - 3.40 represent a moderate level of propriety of bathroom for elderly.

Mean scores $1.81-2.60$ represent a low level of propriety of bathroom for elderly.

Mean scores $1.00-1.80$ represent a lowest level of propriety of bathroom for elderly. 


\section{Result}

\subsection{Investigation of space and risk factors of bathroom accidents of elderly}

Investigation results in a sample of 30 homes currently living by the elderly based on the collected data, the idea and opinion of elderly toward the space, and risk factors of home bathroom accident offered the data to plan for the design and prevent accidents as the problem and cause of enormous losses.

Table 1: Propriety of bathroom environment to support the use by elderly

\begin{tabular}{|c|c|c|c|}
\hline \multirow[b]{2}{*}{ Details of Propriety } & \multicolumn{3}{|c|}{$(n=30)$} \\
\hline & $\overline{\mathbf{x}}$ & S.D. & Level \\
\hline $\begin{array}{l}\text { 1) Suitable size and proportion: } \\
\text { 1.1 Width of doorway } \\
\text { 1.2 Height of sink counter and mirror } \\
\text { 1.3 Height of towel rack } \\
\text { 1.4 Width of space to install toilet bowl }\end{array}$ & $\begin{array}{l}2.10 \\
2.30 \\
1.67 \\
2.63 \\
\end{array}$ & $\begin{array}{l}0.76 \\
0.79 \\
0.61 \\
0.76 \\
\end{array}$ & $\begin{array}{l}\text { Low } \\
\text { Low } \\
\text { Low } \\
\text { Moderate }\end{array}$ \\
\hline $\begin{array}{l}\text { 2) Materials used for the design: } \\
\text { 2.1Flooring materials should be slip-resistant. } \\
\text { 2.2Wall materials should be slip-resistant. } \\
\text { 2.3Reduce the design using materials with sharp corner. } \\
\text { 2.4Design of ramps for uneven floor }\end{array}$ & $\begin{array}{l}1.10 \\
1.23 \\
1.63 \\
1.07 \\
\end{array}$ & $\begin{array}{l}0.31 \\
0.43 \\
0.67 \\
0.25\end{array}$ & $\begin{array}{l}\text { Lowest } \\
\text { Lowest } \\
\text { Low } \\
\text { Lowest }\end{array}$ \\
\hline $\begin{array}{l}\text { 3) Space to accommodate products: } \\
\text { 3.1 Accommodate wheelchair use by elderly } \\
\text { 3.2 Accommodate toilet chair } \\
\text { 3.3 Space available to install grab bars } \\
\text { 3.4 Accommodate other materials, e.g. canes/walkers }\end{array}$ & $\begin{array}{l}1.40 \\
3.33 \\
3.60 \\
2.33 \\
\end{array}$ & $\begin{array}{l}0.86 \\
0.92 \\
0.97 \\
0.99 \\
\end{array}$ & $\begin{array}{l}\text { Lowest } \\
\text { Moderate } \\
\text { High } \\
\text { Low }\end{array}$ \\
\hline $\begin{array}{l}\text { 4) Body movement: } \\
\text { 4.1 Body wash } \\
\text { 4.2 Use of space around sink and mirror } \\
\text { 4.3 Use of toilet bowl } \\
\text { 4.4 Changing clothes and getting dress }\end{array}$ & $\begin{array}{l}2.40 \\
2.07 \\
2.63 \\
2.90 \\
\end{array}$ & $\begin{array}{l}1.10 \\
1.55 \\
1.54 \\
1.49 \\
\end{array}$ & $\begin{array}{l}\text { Low } \\
\text { Low } \\
\text { Moderate } \\
\text { Moderate }\end{array}$ \\
\hline $\begin{array}{l}\text { 5) Enough light in use: } \\
\text { 5.1 Light allowing for clear vision. } \\
\text { 5.2 Causing no impact } \\
\text { 5.3 Adequate number of installed lights } \\
\text { 5.4 Lights corresponding to use behavior }\end{array}$ & $\begin{array}{l}2.60 \\
2.77 \\
3.37 \\
1.30\end{array}$ & $\begin{array}{l}0.77 \\
1.04 \\
0.61 \\
0.47\end{array}$ & $\begin{array}{c}\text { Moderate } \\
\text { Moderate } \\
\text { Moderate } \\
\text { Lowest }\end{array}$ \\
\hline Total & 2.22 & 0.84 & Low \\
\hline
\end{tabular}

As table 1 Suggests, it is currently recognized that living space is particularly important for long-term care of the elderly in order to support the change of Thai society toward the upcoming aged society and it is known that the major problems and concerns for the current situation of elderly living involve accident risk in the use of bathroom space. In Table 1, the width of doorway, the height of sink counter and mirror, and the height of towel rack were at a low level of propriety with mean of 2.10, 2.30, 1.67, respectively, and standard deviation of $0.76,0.79,0.61$, respectively. Features with lowest level of propriety included flooring materials should be slip-resistant with mean of 1.10 and standard deviation of 0.31 ; wall materials should be slip-resistant with mean of 1.23 and standard deviation of 0.43; design of ramps for uneven floor with mean of 1.07 and standard deviation of 0.25; space to accommodate wheelchair use by elderly, and lights corresponding to use behavior with means of 1.40 and 1.30 and standard deviation of 0.86 and 0.47 . It can be observed that the current bathroom is a high risk space of accident especially the choice of inappropriate materials and the failure to support various activities. Moreover, major concern was uneven floor as a primary problem of trips and falls in bathroom. 
Table 2: Propriety of bathroom environment to support elderly use of bathroom at home by different aspects

\begin{tabular}{l|c|c|c}
\hline \multirow{2}{*}{ Details of Propriety by Aspect } & \multicolumn{3}{|c}{$\mathbf{( n = 3 0 )}$} \\
\cline { 2 - 4 } 1) Suitable size and proportion & $\overline{\mathbf{x}}$ & $\mathbf{S . D .}$ & Level \\
2) Materials used for design & 2.18 & 0.73 & Low \\
3) Space to accommodate products & 1.26 & 0.41 & Lowest \\
4) Body movement & 2.67 & 0.93 & Moderate \\
5) Enough light in use & 2.50 & $\mathbf{1 . 4 2}$ & Moderate \\
\hline Total & $\mathbf{2 . 5 1}$ & $\mathbf{0 . 7 2}$ & Moderate \\
\hline
\end{tabular}

As table 2 Depicts the propriety investigation results by aspects, suggesting that the current bathroom space was substandard, failed to support the use by elderly, and was at high risk of domestic bathroom accident of elderly. It was observed in the current housing that the construction design, environment management, and consideration of use behavior in real situation were all inappropriate and ineffective. It was lacked of standards in planning of systematic housing management. For the propriety in each aspect as observed here, suitable size and proportion of bathroom with mean of 2.18 and standard deviation of 0.73 was at a low level; material used for design with mean of 1.26 and standard deviation of 0.41 was at a lowest level; space to support products with mean of 2.67 and standard deviation of 0.93 was at a moderate level; body movement with mean of 2.50 and standard deviation of 1.42 was at a moderate level, enough light in use with mean of 2.51 and standard deviation of 0.72 was at a moderate level. Propriety evaluation of good bathroom features for the use by elderly provided mean of 2.22 and standard deviation of 0.85 , suggesting a low level in overall.

\subsection{Proposed modification guidelines for suitable home bathroom environment for elderly}

Guidelines for modification of home bathroom environment were proposed to help reduce accident risk for the elderly to live in the same place safely and longer. Reducing the occurrence of domestic accident among elderly will help avoid the transfer to stay in hospital or nursing home. This can be done by creating suitable and safe environment that facilitates functionality (Enabling Environments), planning of good design to offer comfort at old age and reduce elderly problems by adopting universal design with 7 key principles (Figure 2). (In a ring, links between UD principles can be understood by consideration of overlapping areas.)

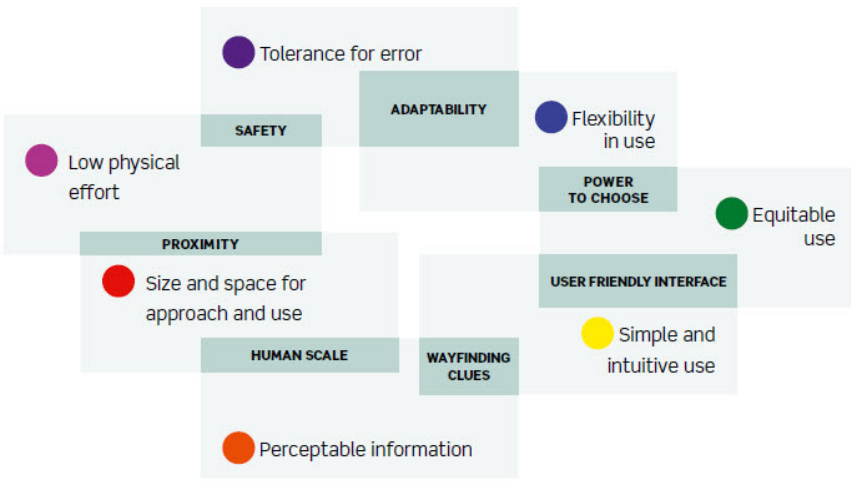

Fig 4: In a ring configuration, overlapping areas between pairs of the principles of universal design, a particular design problem in architecture 
Table 3: Significance of the design issues for modification of home bathroom environment from the in-depth interview with 5 experts (based on the 7 principles of universal design)

\begin{tabular}{|c|c|c|c|}
\hline \multirow{2}{*}{ Principles } & \multicolumn{3}{|c|}{$(n=5)$} \\
\hline & $\overline{\mathbf{x}}$ & S.D. & Level \\
\hline $\begin{array}{l}\text { UD1. Equitable Use } \\
\text { - The design is useful to all and corresponds the need of elderly. }\end{array}$ & 4.40 & 0.55 & High \\
\hline $\begin{array}{l}\text { UD2. Flexible Use } \\
\text { - The design accommodates a wide range of change of each individual. }\end{array}$ & 4.80 & 0.45 & Highest \\
\hline $\begin{array}{l}\text { UD3. Simple and Intuitive Use } \\
\text { - The design is easy to use without complexity and complication to cause difficulties. }\end{array}$ & 4.60 & 0.55 & Highest \\
\hline $\begin{array}{l}\text { UD4. Perceptible Information } \\
\text { - The design helps communicate information that promotes sensory perception of users. }\end{array}$ & 3.80 & 0.84 & High \\
\hline $\begin{array}{l}\text { UD5. Tolerance for Error } \\
\text { - The design minimizes accidental hazards and error in use. }\end{array}$ & 4.60 & 0.55 & Highest \\
\hline $\begin{array}{l}\text { UD6. Low Physical Effort } \\
\text { - The design can be used efficiently and comfortably and with minimum force. }\end{array}$ & 4.20 & 0.84 & Highest \\
\hline $\begin{array}{l}\text { UD7. Size and Space for Approach and Use } \\
\text { - Considering appropriate size and space accessible by use behavior. }\end{array}$ & 4.80 & 0.45 & Highest \\
\hline
\end{tabular}

As table 3 Illustrates the results of in-depth interview with 5 design experts regarding the guidelines and significance of design issues for modification of home bathroom environment (based on the 7 principles of universal design). As Table 1 suggests, the importance should be placed on the followings: the design that accommodates a wide range of change of each individual with mean 4.80 and standard deviation of 0.45 , a highest level; the design should be easy to use without complexity and complication to cause troubles with mean of 4.60 and standard deviation of 0.55 , a highest level; the design minimizes accidental hazards with mean 4.6o and standard deviation of 0.55 , a highest level; the design can be used effectively and comfortably and with minimum force with mean of 4.20 and standard deviation of 0.84 , a high level; considering appropriate size and space accessible by use behavior with mean of 4.80 and standard deviation of 0.45 , a highest level; the design is useful for all and corresponds the need of elderly with mean of 4.40 and standard deviation of 0.55 , a high level; and the design helps communicate information that promote sensory perception of users with mean of 3.80 and standard deviation of 0.84 , a high level. The researcher will take all of these results to propose guidelines for modification of home bathroom environment for elderly.

Table 4: Symbols attached to the design to explain the meaning, concept rationale synthesis to relate good design work

\begin{tabular}{|c|c|c|}
\hline Symbol & Detail of Design Concept & $\begin{array}{l}\text { Relevance to } \\
\text { Principle }\end{array}$ \\
\hline A & $\begin{array}{l}\text { The door should be } 1 \text { meter wide as sliding door to help reduce normal door swing space and allow } \\
\text { for convenient use of wheelchair and stepping into the bathroom with walker or other devices. }\end{array}$ & $\begin{array}{l}\text { UD1, UD5, UD6, } \\
\text { UD7 }\end{array}$ \\
\hline B & $\begin{array}{l}\text { The design of U-shape drainage ditch covered with grates by the same level of bathroom floor tiles to } \\
\text { accommodate user's continuous path of travel in wheelchair and also avoid trips and falls. }\end{array}$ & $\mathrm{UD}_{3}, \mathrm{UD}_{5}, \mathrm{UD} 6$ \\
\hline $\mathrm{C}$ & $\begin{array}{l}\text { The design of slip-resistant floor patch material around the entry point or the internal area not in use } \\
\text { as caution signs to help warning with walking or stopping wheelchair. }\end{array}$ & $\begin{array}{l}\text { UD1, UD4, UD5, } \\
\text { UD6 }\end{array}$ \\
\hline $\mathrm{D}$ & $\begin{array}{l}\text { Management of open space in bathroom for elderly should provide a barrier-free space of minimum } \\
1.25-2.00 \text { meters in diameter to accommodate circulation space of devices and wheelchair. }\end{array}$ & $\begin{array}{l}\text { UD1, UD2, UD3, } \\
\text { UD7 }\end{array}$ \\
\hline E & $\begin{array}{l}\text { Floor and wall tiling materials should be non-glazed or non-slip to prevent tactile hazard of trips or } \\
\text { falls when using. }\end{array}$ & $\begin{array}{l}\text { UD1, UD4, UD5, } \\
\text { UD6 }\end{array}$ \\
\hline $\mathrm{F}$ & $\begin{array}{l}\text { Preparation of space to accommodate various facilities such as storages for clothes or necessary living } \\
\text { items of elderly. }\end{array}$ & UD1, UD6, UD7 \\
\hline G & $\begin{array}{l}\text { Installing horizontal grab bars around internal area of the bathroom with } 3-4 \mathrm{~cm} \text { diameter handle } \\
\text { size, non-slip materials, ease of use, hazard-free. }\end{array}$ & $\begin{array}{l}\text { UD1, UD3, UD5, } \\
\text { UD6, UD7 }\end{array}$ \\
\hline $\mathrm{H}$ & $\begin{array}{l}\text { The design of partition to separate wet and dry area should not be too high or confined and should be } \\
\text { around } 1.40 \text { meters high allowing to see on the inside in case of emergency. }\end{array}$ & UDı, UD \\
\hline
\end{tabular}




\begin{tabular}{|c|c|c|}
\hline Symbol & Detail of Design Concept & $\begin{array}{l}\text { Relevance to } \\
\text { Principle }\end{array}$ \\
\hline I & $\begin{array}{l}\text { Wall and grab bars are in place at the side to assist with stability when getting up and sitting down } \\
\text { using the toilet bowl. }\end{array}$ & $\begin{array}{l}\text { UD2, UD5, UD6, } \\
\text { UD7 }\end{array}$ \\
\hline $\mathrm{J}$ & $\begin{array}{l}\text { Fold-up wall mounted shower seat is installed to enable elderly sitting down showering, with a height } \\
\text { of } 0.45 \text { meter above the floor. }\end{array}$ & $\begin{array}{l}\text { UD1, UD2, UD6, } \\
\text { UD7 }\end{array}$ \\
\hline K & $\begin{array}{l}\text { lable in the area of getting up-sitting down, with } 3-4 \mathrm{~cm} \text {. diameter handle } \\
\text { r from the floor, and non-slip material easy to use. }\end{array}$ & $\begin{array}{l}\mathrm{UD}_{1}, \mathrm{UD}_{3}, \mathrm{UD}_{5} \\
\text { UD6, UD7 }\end{array}$ \\
\hline $\mathrm{L}$ & ability beside toilet bowl should be 3-4 cm. diameter handle size and & $\begin{array}{l}\text { UD1, UD3, UD5, } \\
\text { UD6, UD7 }\end{array}$ \\
\hline M & $\begin{array}{l}\text { Lever handle faucets are provided to reduce using force, and the sink is half mounted on countertop } \\
\text { with open space beneath and no more than } 75 \mathrm{~cm} \text {. high to accommodate convenient use by elderly in } \\
\text { wheelchair. }\end{array}$ & $\begin{array}{l}\text { UD1, UD3, UD6, } \\
\text { UD7 }\end{array}$ \\
\hline
\end{tabular}

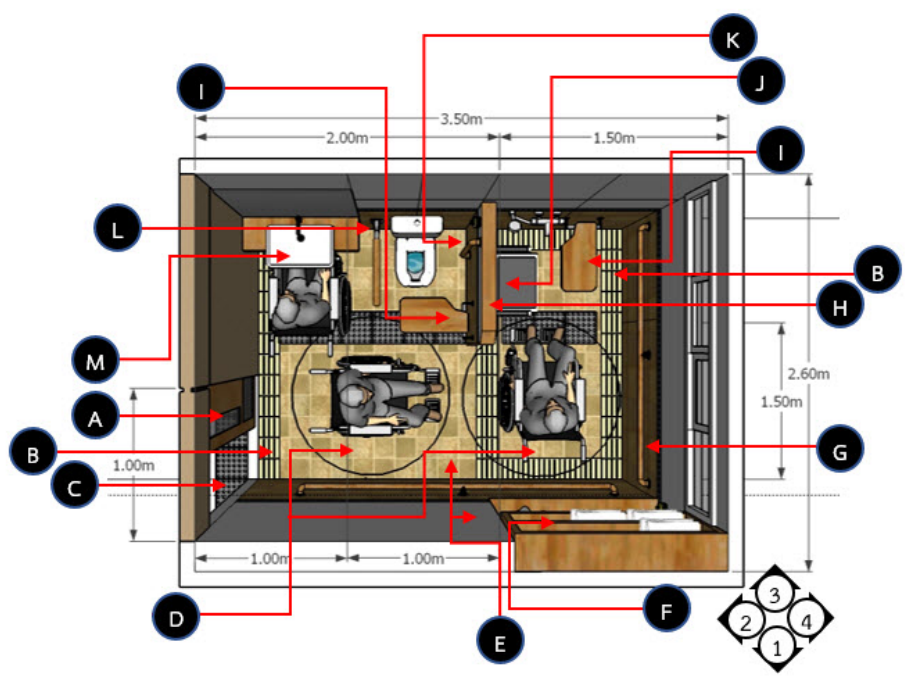

Fig 5: Floor plan of the design concept of home bathroom for elderly

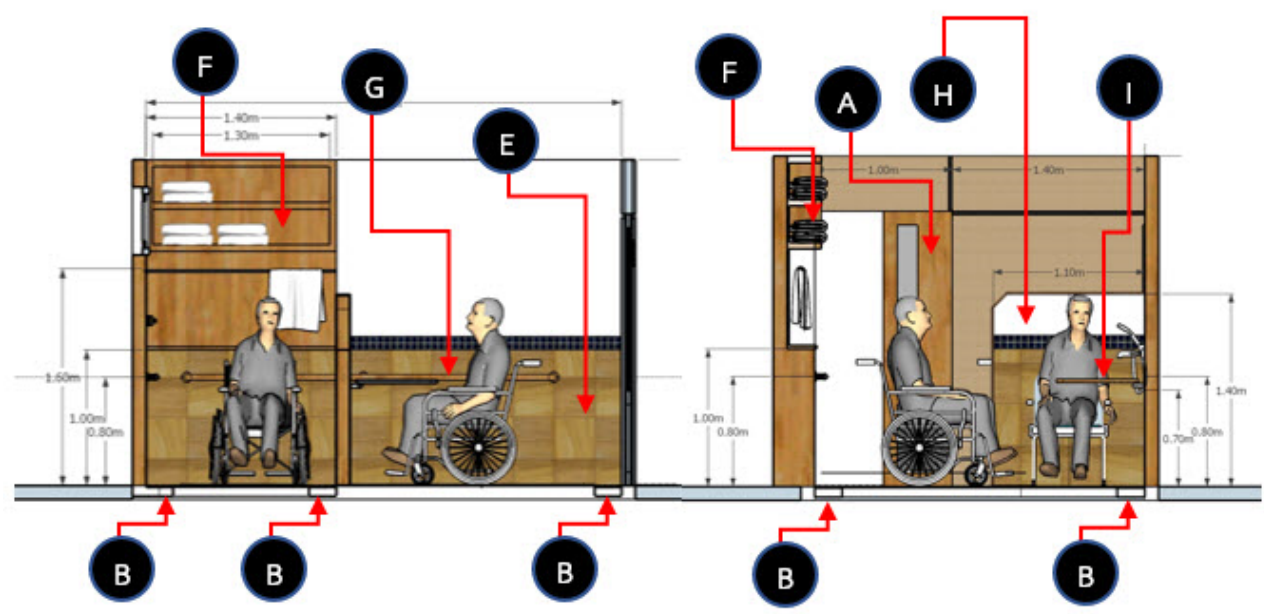

Fig 6: View 1 and view 2 of the design concept of home bathroom for elderly 


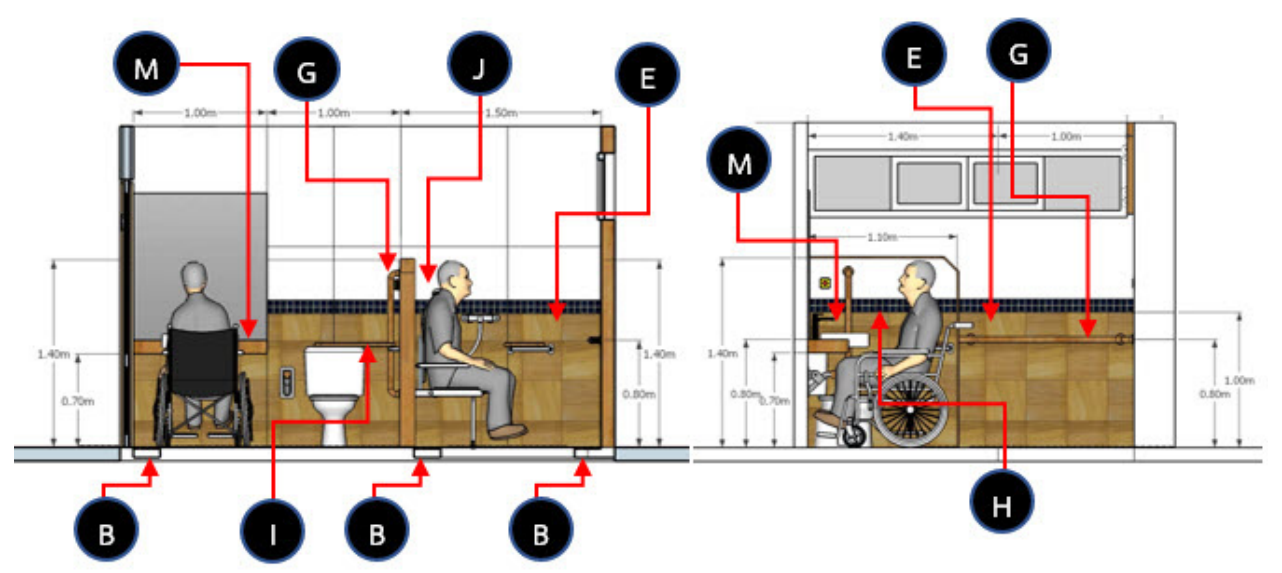

Fig 7: View 3 and view 4 of the design concept of home bathroom for elderly

\section{Conclusion}

The concept of management of appropriate home bathroom environment for elderly takes into consideration the management of spaces and risk factors of accidents of elderly in their home. It not only focuses on good ventilation as an architectural principle but also the tenet of universal design with 7 key principles to accommodate proper use by elderly. The preparation of environmental condition should respond the basic needs of general elderly. For example, the doorway is approximately 1 meter wide as sliding door to reduce normal door swing space and facilitate wheelchair and stepping inside the bathroom. The design of sink half-mounted to countertop is strong enough to bear the weight when use in standing position, installed with 0.75 meter high from the upper edge and 0.65 high from the lower edge and tiled with granite for easy care, including lever handle mixer faucet to reduce force when use, and a mirror with the bottom edge 0.90 above the floor allowing to see the whole body. Most important is safety as bathroom is the place where accidents mostly took place among elderly. The design should consider even surface of the floor inside and outside of the bathroom while allowing good water drainage. It is suitable to choose floor tiles with rough, non-slop surface but giving a sense of warmth. Devices and vertical grab bars to support the body are fixed around the space inside the bathroom, with 3-4 cm diameter handle size and located at 0.80 meter high from the floor, using non-slip materials easy to use for body support. Bathroom space for elderly should be $1.50-2.00$ meters minimum in diameter and barrier-free to accommodate the circulation of devices and wheelchair. Space is prepared for caregiver to assist in bathing and the space requires some slope for water to flow quickly to drain pipe, including shower seat with 0.45 meter high and easy to clean, height adjustable shower, lever handle faucet, and grab bars for body support alongside. To prepare appropriate environment for elderly both interior and exterior of the bathroom, it is necessary to know about risk factors and real problems so that proper care and prevention standards can be established.

\section{Acknowledgments}

This research project would not have been possible without the people. The author support of many wishes to express gratitude to an adviser, Assistant Professor Dr.Somchai Seviset and Associate Professor Dr. Songwut Eakwutvongsa who was abundantly helpful and offered invaluable support, guidance, and assistance this study would have been successful. 


\section{References}

Archbold, P.G., Stewart, B.J., Greenlick, M.R., \& Harvath, T. (1990). Mutuality and Preparedness as Predictora of Caregiver Role Strain. Research in Nursing \& Health, 13(6), 375-84.

Cieirelli, V. (1981). Helping Elderly Parents: The Role of Adult Children. Boston: Auburn House.

Census and Statistics Department (2012). Population census thematic report: Older persons. Retrieved June 2014, from http://www.census2o11.gov.hk/pdf/older-persons.pdf.

Census and Statistics Department (2013). Population and household statistics by district council district. Retrieved June 2014, from http://www.censtatd.gov.hk/hkstat/sub/sp15o.jsp?productCode=B1130301.

Connell, Bettye Rose, Jon A. Sanford, and Donna Lewis. "Therapeutic Effects of an Outdoor Activity Program on Nursing Home Residents With Dementia." Journal of Housing for the Elderly 21, (3-4): 194-209. Accessed August 11, 2016. doi:10.1300/jo81v21no3_10.

Chaninprasert V.(2006). Anthropometric Study of Thai Elderly. A Thesis, Industrial Engineering, King Mongkut's University of Technology North Bangkok.

Ministry of Social Development and Human Security. (2004). Elderly Person Act, B.E. 2546 (2003). Bangkok: J.S.

Ministry of Social Development and Human Security. (2010). The 2nd National Plan on the Elderly $2002-2021$. Bangkok: Theppenvanich.

Ministry of Social Development and Human Security. (2009). Situation Of the Thai Elderly 20o8. Bangkok: TQP.

Molly Follette Story, M.S. IDSA. Principles of Universal Design. Universal Design Handbook. New York: Mc Grow Hill. 2001.

Pynoos, J., Mayeda, A., \& Lee, C. (2003). Home Modification Resource Guide. Los Angeles, CA: University of Southern California, The National Resource Center on Supportive Housing and Home Modification.

Sandra, H. C. (1980). Designing for aging: Pattern of use (2nd ed.). London: The MIT Press. The Association of Siamese Architects under the Royal Patronage of His Majesty the King (2009). Universal Design Code of Practice. Bangkok: J.S. 